\title{
AVALIAÇÃO DE INDICADORES DE USO DIVERSO COMO INIBIDORES DE CORROSÃO
}

\author{
Sheila Pressentin Cardoso*, Fernanda Almeida dos Reis, Filipe Castelletti Massapust, Jeremias de Freitas Costa, Larissa \\ Silveira Tebaldi, Luiz Felipe Leal de Araújo, Marcus Vinícius Augusto da Silva e Thiago Sousa de Oliveira \\ Centro Federal de Educação Tecnológica de Química de Nilópolis, Rua Lúcio Tavares, 1045, 26530-060 Nilópolis - RJ \\ José Antônio da Cunha Ponciano Gomes \\ Engenharia Metalúrgica e de Materiais, Universidade Federal do Rio de Janeiro, Bloco F, Cidade Universitária, \\ 21949-900 Rio de Janeiro - RJ \\ Eduardo Hollauer \\ Departamento de Físico-Química, Instituto de Química, Universidade Federal Fluminense, Outeiro de São João Batista, s/n, \\ 24020-150 Niterói - RJ
}

Recebido em 13/4/04; aceito em 3/3/05; publicado na web em 30/6/05

\begin{abstract}
EVALUATION OF COMMON-USE INDICATORS AS CORROSION INHIBITORS. Very often hydrochloric acid is employed in acidification operations aiming to dissolve the mineral matrix in petroleum wheel operations, which always require intense use of corrosion inhibitors. This work presents an evaluation of common indicators, phenolfthaleine, fluorescein, methylene blue, alizarine $\mathrm{S}$ and methyl orange, as corrosion inhibitors for carbon steel in $\mathrm{HCl} 15 \% \mathrm{w} / \mathrm{v}$ at temperatures of 26,40 and $60{ }^{\circ} \mathrm{C}$. Fluorescein and methyl orange show excelent corrosion inhibition efficiencies at $26{ }^{\circ} \mathrm{C}$; however at $60{ }^{\circ} \mathrm{C}$ only fluorescein shows good corrosion inhibition when employed with alcohol and/or formaldehyde. For the fluorescein $1 \% \mathrm{w} / \mathrm{v}+$ formaldehyde $0.6 \% \mathrm{w} / \mathrm{v}$ mixture we present polarization and impedance curves and adsorption isotherms.
\end{abstract}

Keywords: corrosion inhibitor; acidification; fluorescein.

\section{INTRODUÇÃO}

A indústria do petróleo é um dos setores onde há grande incidência de problemas associados a processos de corrosão, que podem ocorrer nas etapas de extração de óleo e gás, durante o transporte, em operações de refino e, também, na estocagem dos produtos finais. No que se refere à etapa de extração, destaca-se a operação de acidificação (acidificação de matriz) realizada com o objetivo de promover a estimulação de poços de petróleo. Essa estimulação torna-se necessária como consequiência do depósito de substâncias sólidas que obstruem parcialmente os espaços porosos e canais da matriz rochosa, diminuindo assim a capacidade de produção do poço ${ }^{1}$. Na acidificação de matriz, uma solução ácida é usada para dissolver parcialmente os minerais presentes na formação rochosa, recuperando ou aumentando a permeabilidade da estrutura. O ácido clorídrico entre 15 e $28 \%$ p/v é usualmente empregado quando da presença de rochas carbonáticas, sendo a mistura ácido clorídrico $12 \%$ p/v e fluorídrico $3 \%$ p/v empregada em rochas contendo silicatos ${ }^{2}$.

A utilização do ácido clorídrico ou da mistura ácido clorídrico/ fluorídrico apresenta, contudo, limitações. A principal é a elevada taxa de corrosão imposta aos diferentes materiais metálicos que compõem a estrutura do poço. Conseqüentemente, para preservação da integridade dos poços o uso de inibidores de corrosão específicos é essencial, sendo que a natureza e a concentração dos inibidores dependerá do fluido de acidificação usado, da composição dos metais envolvidos e da temperatura na qual é realizada a operação de acidificação ${ }^{3}$. Adicionalmente, o inibidor de corrosão deverá ser eficiente na proteção de todas as ligas com as quais o fluido entrar em contato, garantindo um valor limite de taxa de corrosão que não implique em dano significativo aos componentes

*e-mail: sheilapc@cefeteq.br metálicos que integram a estrutura do poço. Esse valor máximo admissível varia de acordo com fatores operacionais, características do poço, e do conhecimento prévio das operações de acidificação anteriormente realizadas. Um dos valores limite sugeridos na literatura, situa-se em torno 200 mpy (milésimos de polegada ao ano), correspondendo a uma perda de espessura de 5,0 $\mathrm{mm} /$ ano quando a corrosão for de morfologia exclusivamente uniforme, e de 100 mpy, correspondendo a $2,5 \mathrm{~mm} /$ ano quando a morfologia do processo corrosivo apresentar componentes de corrosão localizada ${ }^{4}$.

Os inibidores indicados para proteger os materiais metálicos em meios ácidos são os inibidores de adsorção, que se adsorvem sobre as regiões catódicas e/ou anódicas do metal, protegendo-o. Os inibidores de adsorção são normalmente compostos orgânicos contendo insaturações e/ou grupamentos fortemente polares contendo nitrogênio, oxigênio ou enxofre. Como ex., podemos citar aminas, aldeídos, mercaptanas, compostos heterocíclicos nitrogenados, compostos contendo enxofre e compostos acetilênicos 5 .

Neste trabalho avaliou-se a eficiência de cinco compostos orgânicos - fenolftaleína, fluoresceína, azul de metileno, alizarina $\mathrm{S}$ e alaranjado de metila - como matéria ativa básica para a formulação de potenciais inibidores de corrosão para o aço carbono UNSG4130, em solução de $\mathrm{HCl} 15 \%$ p/v (4,1 mol/L). Os compostos escolhidos para teste são substâncias usadas como indicadores $(\mathrm{pH}$ ou de adsorção), que possuem características estruturais similares àquelas encontradas em inibidores empregados em operações de acidificação.

\section{PARTE EXPERIMENTAL}

A eficiência dos indicadores como inibidores de corrosão foi avaliada empregando-se ensaios de perda de massa, ensaios eletroquímicos (polarização e impedância) e determinando-se também, a isoterma do processo de adsorção metal/inibidor. 
Os ensaios de perda de massa foram inicialmente realizados à temperatura de $26^{\circ} \mathrm{C}$, utilizando-se recipientes plásticos com agitação constante da solução mediante o uso de agitador magnético. Considerando que a temperatura nos poços varia entre 60 e $100^{\circ} \mathrm{C}$, os ensaios gravimétricos foram repetidos à temperatura de $60^{\circ} \mathrm{C}$, de modo a aproximarem-se das condições reais de operação, mas somente para os compostos de maior eficiência pré-selecionados na etapa anterior. Estes ensaios foram realizados em autoclaves cilíndricas revestidas de teflon, colocadas em estufa de rolos de modo a garantir uniformidade de aquecimento e agitação do sistema. Foram usados em cada ensaio dois corpos de prova imersos em $350 \mathrm{~mL}$ de $\mathrm{HCl} 15 \% \mathrm{p} / \mathrm{v}$, adicionando-se $2 \% \mathrm{p} / \mathrm{v}$ dos compostos orgânicos. Os corpos de prova possuíam dimensão média de $1,5 \times 0,8 \times 0,8 \mathrm{~cm}$, e orifício central de $0,35 \mathrm{~cm}$ para fixação. Foram lixados, desengordurados, lavados com água destilada, secos e pesados com precisão de quatro casas decimais. Realizou-se o mesmo procedimento após o término dos ensaios de imersão.

A intensidade do processo corrosivo foi expressa a partir do cálculo da taxa de corrosão, em milésimos de polegada ao ano (mpy), conforme indicação da norma ASTM G1-726, empregandose a Equação 1

Taxa de corrosão $=(\mathrm{K} . \mathrm{W}) / \mathrm{A}$ t $\rho$

onde $\mathrm{K}$ é uma constante $\left(5,45 \times 10^{6}\right.$ para unidades em mpy), W a perda de massa em $\mathrm{g}, \mathrm{A}$ a área exposta $\mathrm{em}^{2} \mathrm{~cm}^{2}$, $\mathrm{t}$ o tempo de exposição em $\mathrm{h}$, e $\rho$ a massa específica do material em $\mathrm{g} / \mathrm{cm}^{3}$. Como valor final utilizou-se a média das taxas de corrosão obtidas para os corpos de prova.

Os ensaios de polarização foram realizados com um potenciostato-galvanostato Omnimetra modelo PG-05, operando no modo potenciostático em configuração de três eletrodos. O potencial imposto foi variado manualmente. Utilizou-se uma célula de vidro com capacidade para $500 \mathrm{~mL}$ de solução, contra eletrodo de platina, eletrodo de referência de calomelano saturado e corpos de prova embutidos em resina com $0,5 \mathrm{~cm}^{2}$ de área exposta ao meio corrosivo. A temperatura do recipiente foi mantida constante, com o auxílio de uma fita aquecedora em contato externo com a célula de vidro. Para evitar perda da solução por evaporação, acoplou-se à célula um sistema de refluxo. Os ensaios de impedância eletroquímica foram realizados na mesma célula dos ensaios de polarização, empregando-se um analisador de funções de transferência Solartron SI 1280. A faixa de frequiência avaliada foi entre $1 \mathrm{KHz}$ e $10 \mathrm{mHz}$, mantendo-se o eletrodo de trabalho polarizado em seu potencial de corrosão.

De modo a avaliar o processo de adsorção dos compostos sobre a superfície metálica, foram traçadas as isotermas de adsorção de Langmuir, Temkin e Frumkin, mediante as Equações ${ }^{7}$ apresentadas na Tabela 1. A fração de recobrimento $(\theta)$ foi calculada a partir das taxas de corrosão provenientes dos ensaios de perda de massa a $60^{\circ} \mathrm{C}$ (Equação 2), obtidas para soluções contendo $1 \times 10^{-2}$, $1 \times 10^{-3}, 5 \times 10^{-4}$ e $1 \times 10^{-4} \mathrm{p} / \mathrm{v}$ dos compostos orgânicos. Onde $v_{\mathrm{o}}$ equivale à taxa de corrosão do ensaio em branco e $v$ à taxa de corrosão na presença do inibidor.

$\theta=\left(v_{o}-v\right) / v_{o}$

\section{RESULTADOS E DISCUSSÃO}

Os resultados dos ensaios de perda de massa do aço carbono, realizados a $26^{\circ} \mathrm{C}$, em solução $15 \%$ p/v de $\mathrm{HCl}$ (branco) e na presença de $2 \% \mathrm{p} / \mathrm{v}$ dos compostos orgânicos são apresentados na Tabela 2 . O uso de uma concentração de $2 \%$ p/v foi baseada em reco-
Tabela 1. Equações para as isotermas de Langmuir, Temkin e Frumkin onde $\theta=$ fração de recobrimento, $\mathrm{C}=$ concentração do inibidor $(\mathrm{mol} / \mathrm{L}), \mathrm{K}=$ constante de equilíbrio de adsorção e $\mathrm{g}=$ grau de interação lateral entre as moléculas adsorvidas

\begin{tabular}{ll}
\hline Isoterma & Equação \\
\hline Langmuir & $\theta /(1-\theta)=\mathrm{KC}$ \\
Temkin & $\log (\theta / \mathrm{C})=\log \mathrm{K}+\mathrm{g} \theta$ \\
Frumkin & $\log (\theta /(1-\theta) \cdot \mathrm{C})=\log \mathrm{K}+\mathrm{g} \theta$ \\
\hline
\end{tabular}

mendação da literatura, que sugere que a quantidade total de matéria ativa em fluidos de acidificação de matriz não deve ser superior a este valor ${ }^{8}$. O alaranjado de metila (AM) e a fluoresceína (FL) apresentaram taxa de corrosão de 179,59 e 102,21 mpy, respectivamente, sendo dos cinco compostos testados, os únicos que geraram taxas de corrosão menores que 200 mpy. A fenolftaleína foi o composto de pior desempenho, com o azul de metileno e a alizarina $\mathrm{S}$ apresentando taxas de corrosão próximas de 200 mpy. Esses resultados foram adotados como critério preliminar de seleção, levando à retirada da fenolftaleína, azul de metileno e alizarina $\mathrm{S}$ dos ensaios subseqüentes, presumindo-se que a elevação da temperatura acarretaria um aumento da taxa de corrosão, excedendo o valor limite adotado de 200 mpy.

Tabela 2. Taxa de corrosão para o aço carbono a $26^{\circ} \mathrm{C}$, em solução $15 \% \mathrm{p} / \mathrm{v}$ de $\mathrm{HCl}$ (branco) e na presença de $2 \% \mathrm{p} / \mathrm{v}$ dos compostos testados

\begin{tabular}{lc}
\hline Composto & Taxa de Corrosão (mpy) \\
\hline Branco & 1572,79 \\
Alaranjado de metila & 179,59 \\
Alizarina S & 328,18 \\
Azul de metileno & 276,18 \\
Fenolftaleína & 1137,17 \\
Fluoresceína & 102,21 \\
\hline
\end{tabular}

Devido à baixa solubilidade da fluoresceína em meio aquoso, os ensaio de perda de massa a $60{ }^{\circ} \mathrm{C}$ foram realizados empregando-se $1 \%$ p/v de FL e AM. Nessa nova condição de teste, nenhum dos compostos apresentou taxa de corrosão abaixo de $200 \mathrm{mpy}$, como pode ser verificado na Tabela 3 .

Tabela 3. Taxa de corrosão para o aço carbono a $60{ }^{\circ} \mathrm{C}$, em solução $15 \% \mathrm{p} / \mathrm{v}$ de $\mathrm{HCl}$ (branco) e na presença de $2 \% \mathrm{p} / \mathrm{v}$ de alaranjado de metila e fluoresceína

\begin{tabular}{lc}
\hline Composto & Taxa de Corrosão (mpy) \\
\hline Branco & 4800,16 \\
Alaranjado de metila & 769,12 \\
Fluoresceína & 217,33 \\
\hline
\end{tabular}

O valor de 217,33 mpy obtido para taxa de corrosão na presença da FL encontra-se próximo ao limite de aceitação, de modo que algumas considerações podem ser levantadas visando otimizar sua eficiência. Devido à pouca solubilidade da fluoresceína em meio aquoso, uma etapa inicial de solubilização em etanol $(6 \mathrm{~mL})$ foi testada, assim como a adição de formaldeído $(0,6 \% \mathrm{p} / \mathrm{v})$, já descrita por Oliveira ${ }^{8}$ que comprovou maior inibição do processo corrosivo quando na presença do mesmo. Vale esclarecer que etanol e formaldeído não são considerados matérias ativas nas formulações 
Tabela 4. Taxa de corrosão para o aço carbono a $60{ }^{\circ} \mathrm{C}$, em solução de $\mathrm{HCl} 15 \%$ p/v na presença de fluoresceína, etanol e formaldeído

\begin{tabular}{lcc}
\hline Solução & Taxa de corrosão (mpy) & Eficiência(\%) \\
\hline Fluoresceína 1\% p/v + etanol $(6 \mathrm{~mL})$ & 182,37 & 96,29 \\
Fluoresceína 1\% p/v + formaldeído 0,6\% p/v & 140,01 & 97,08 \\
Fluoresceína 1\% p/v + etanol $(6 \mathrm{~mL})+$ formaldeído 0,6\% p/v & 143,79 & 97,00 \\
\hline
\end{tabular}

de inibidores, e sim, aditivos. Sendo assim, os ensaios de perda de massa foram repetidos para a $\mathrm{FL}$, a $60{ }^{\circ} \mathrm{C}$, adicionando-se etanol e/ ou formadeído à solução contendo $\mathrm{HCl} 15 \%$ p/v e $1 \%$ p/v de FL (Tabela 4). Esta adição de etanol e formaldeído levou à obtenção de taxas de corrosão abaixo de $200 \mathrm{mpy}$, sendo a melhor resposta observada em presença de $1 \% \mathrm{p} / \mathrm{v}$ de fluoresceína $+0,6 \% \mathrm{p} / \mathrm{v}$ de formaldeído, obtendo-se uma taxa de corrosão de 140,01 mpy. Desta forma, os ensaios subseqüentes foram realizados somente para esta mistura. A Figura 1 apresenta a fórmula estrutural da fluoresceína.<smiles>O=C(O)c1ccccc1-c1c2ccc(=O)cc-2oc2cc(O)ccc12</smiles>

Figura 1. Fórmula estrutural da fluoresceína

Para caracterizar a resposta eletroquímica da interface metal/ inibidor, foram determinadas curvas de polarização anódica e catódica, a $60{ }^{\circ} \mathrm{C}$, para a mistura fluoresceína $1 \% \mathrm{p} / \mathrm{v}+$ formaldeído $0,6 \% \mathrm{p} / \mathrm{v}$, e obtidos diagramas de impedância eletroquímica para a mesma mistura, em temperaturas de 26,40 e $60^{\circ} \mathrm{C}$.

A Figura 2 apresenta as curvas de polarização anódica e catódica do ensaio em branco e na presença da mistura testada. Observa-se um processo de dissolução ativa do aço carbono, que se mantém mesmo na presença da FL. A presença do inibidor altera o potencial de corrosão do aço em relação ao branco, isto é, o valor de $\mathrm{E}_{\text {corr }}$ foi deslocado no sentido anódico em torno de $45 \mathrm{mV}_{\text {ecs }}$, sugerindo que o efeito inibidor se dá pela presença da formação de um filme nos sítios anódicos. Esta análise é confirmada pela redução da den-

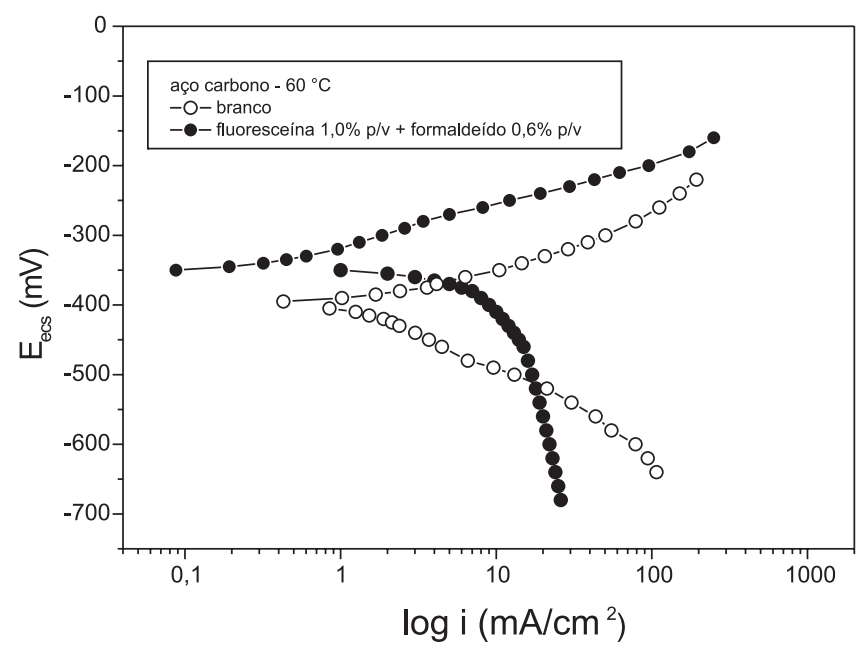

Figura 2. Curvas de polarização anódica e catódica do aço carbono a $60^{\circ} \mathrm{C}$, em solução de $\mathrm{HCl} 15 \%$ p/v (branco) e na presença de fluoresceína $1 \%$ p/v + formaldeído $0,6 \% \mathrm{p} / \mathrm{v}$ sidade de corrente anódica, enquanto que a corrente catódica sofre aumento em relação ao branco até um potencial de $-500 \mathrm{mV}_{\text {ecs }}$ passando, então, a apresentar menores valores de corrente.

As medidas de impedância eletroquímica a $26^{\circ} \mathrm{C}$, para os ensaios em branco e na presença da mistura são apresentadas na Figura 3. A obtenção no Diagrama de Nyquist de semicírculos irregulares, já relatada por Bentes ${ }^{9}$, aliada a uma significativa dispersão dos valores medidos em baixa freqüência, dificulta a análise desses diagramas, assim como a obtenção dos valores de resistência à polarização $\left(\mathrm{R}_{\mathrm{p}}\right)$ ou resistência a transferência de Carga $\left(\mathrm{R}_{\mathrm{tc}}\right)$. Essa dispersão se verifica em função da natureza instável do processo de corrosão em meios fortemente ácidos e aquecidos. Contudo, observa-se uma tendência ao aumento de $\mathrm{R}_{\text {tc }}$ mediante adição do inibidor, indicando redução no processo de dissolução e, conseqüentemente, maior proteção do material quando na presença da mistura testada. O diagrama de impedância obtido em meio ácido não inibido revela a presença de um arco capacitivo seguido de uma resposta indutiva, enquanto que na presença da fluoresceína e aditivo verificam-se dois arcos capacitivos seguidos de resposta indutiva em baixa frequiência. Esse resultado sugere que o segundo arco capacitivo verificado em baixa freqüência poderia estar relacionado com o próprio processo de adsorção do inibidor. As mudanças no diagrama sugerem ainda que ocorreriam alterações no mecanismo de dissolução do metal, e não apenas uma atenuação da intensidade de dissolução. A definição destes mecanismos exigiria a realização de experimentos complementares, variando-se as condições de transporte de massa no sistema. Tal objetivo, contudo, extrapola o escopo do trabalho.

O comportamento do sistema mediante variação da temperatura é apresentado na Figura 4, tendo sido realizados ensaios de impedância a 26,40 e $60{ }^{\circ} \mathrm{C}$. Observa-se uma tendência na redução dos valores de impedância em baixa freqüência mediante aumento da temperatura, o que sugere uma redução dos valores de resistên-

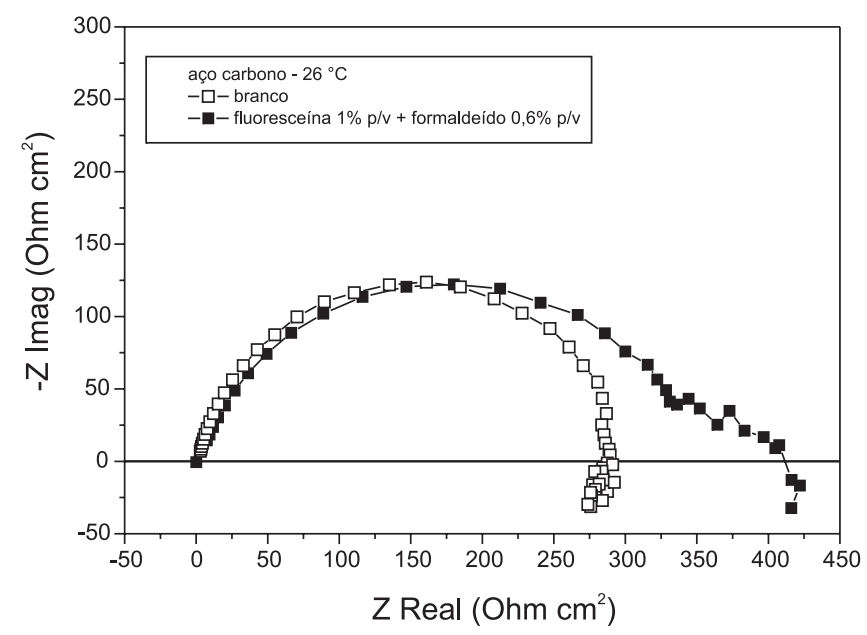

Figura 3. Impedância eletroquímica do aço carbono a $26{ }^{\circ} \mathrm{C}$, em solução de $\mathrm{HCl} 15 \% \mathrm{p} / \mathrm{v}$ (branco) e na presença de fluoresceína $1 \% \mathrm{p} / \mathrm{v}+$ formaldeído $0,6 \% \mathrm{p} / \mathrm{v}$ 
cia à transferência de carga que indicaria, por sua vez, menor proteção e maiores taxas de corrosão em temperaturas crescentes.

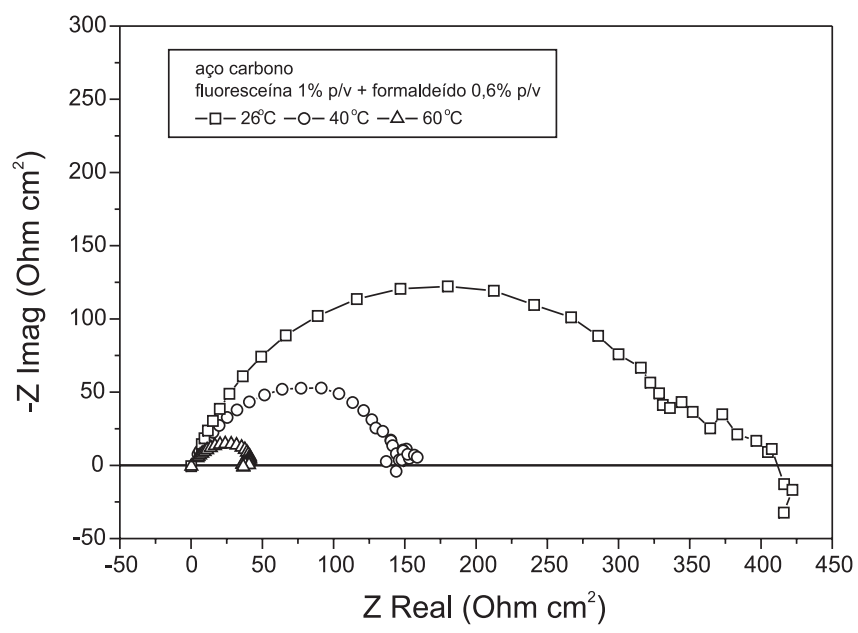

Figura 4. Impedância eletroquímica do aço carbono na presença de $\mathrm{HCl}$ $15 \% p / v+$ fluoresceína $1 \% p / v+$ formaldeído $0,6 \% p / v$, a 26, 40 e $60{ }^{\circ} \mathrm{C}$

Os gráficos das isotermas de adsorção foram traçados a partir da fração de recobrimento $(\theta)$, calculada para diferentes concentrações de fluoresceína, apresentadas na Tabela 5. Das três isotermas de adsorção testadas, obteve-se o melhor ajuste para a isoterma de Lagmuir $^{10}$ (Figura 5a), com R ${ }^{2}=0,998$.

Tabela 5. Concentração de fluoresceína e fração de recobrimento obtidas a $60{ }^{\circ} \mathrm{C}$

\begin{tabular}{ccc}
\hline Concentração\% (p/v) & Concentração $(\mathrm{mol} / \mathrm{L})$ & $\theta$ \\
\hline $1 \times 10^{-2}$ & $3,0 \times 10^{-4}$ & 0,9657 \\
$1 \times 10^{-3}$ & $3,0 \times 10^{-5}$ & 0,7462 \\
$5 \times 10^{-4}$ & $1,5 \times 10^{-5}$ & 0,6753 \\
$1 \times 10^{-4}$ & $3,0 \times 10^{-6}$ & 0,6365 \\
\hline
\end{tabular}

A energia livre do processo de adsorção $\left(\Delta \mathrm{G}_{\mathrm{ads}}\right)$ poder ser calculada por intermédio da Equação 3, onde K representa a constante de equilíbrio de adsorção, obtida a partir da isoterma de Langmuir, e o valor de 55,5 refere-se à concentração (mol/L) da água. A adsorção da fluoresceína sobre a superfície do aço carbono possui $\Delta \mathrm{G}_{\text {ads }}=-42,72 \mathrm{KJ} / \mathrm{mol}$, caracterizando-se como um processo de adsorção química.

$\mathrm{K}=(1 / 55,5) \exp \left(-\Delta \mathrm{G}_{\mathrm{ads}} / \mathrm{RT}\right)$

A isoterma de Temkin (Figura 5b) também apresentou boa correlação com $R^{2}=0,917$. A pior correlação foi obtida para a isoterma de Frumkin (Figura 5c), com $\mathrm{R}^{2}=0,434$. O valor negativo de $\mathrm{g}=$ -4,90 para o grau de interação lateral, que foi obtido da análise dos resultados ajustados para a isoterma de adsorção de Temkin, indica que a interação lateral entre as moléculas do adsorbato sobre a superfície metálica é repulsiva.

\section{CONCLUSÃO}

Dos cinco compostos analisados, a fluoresceína e o alaranjado de metila proporcionaram, a $26{ }^{\circ} \mathrm{C}$, taxa de corrosão abaixo dos 200 mpy adotado como limite aceito para taxas de corrosão em operações de acidificação.
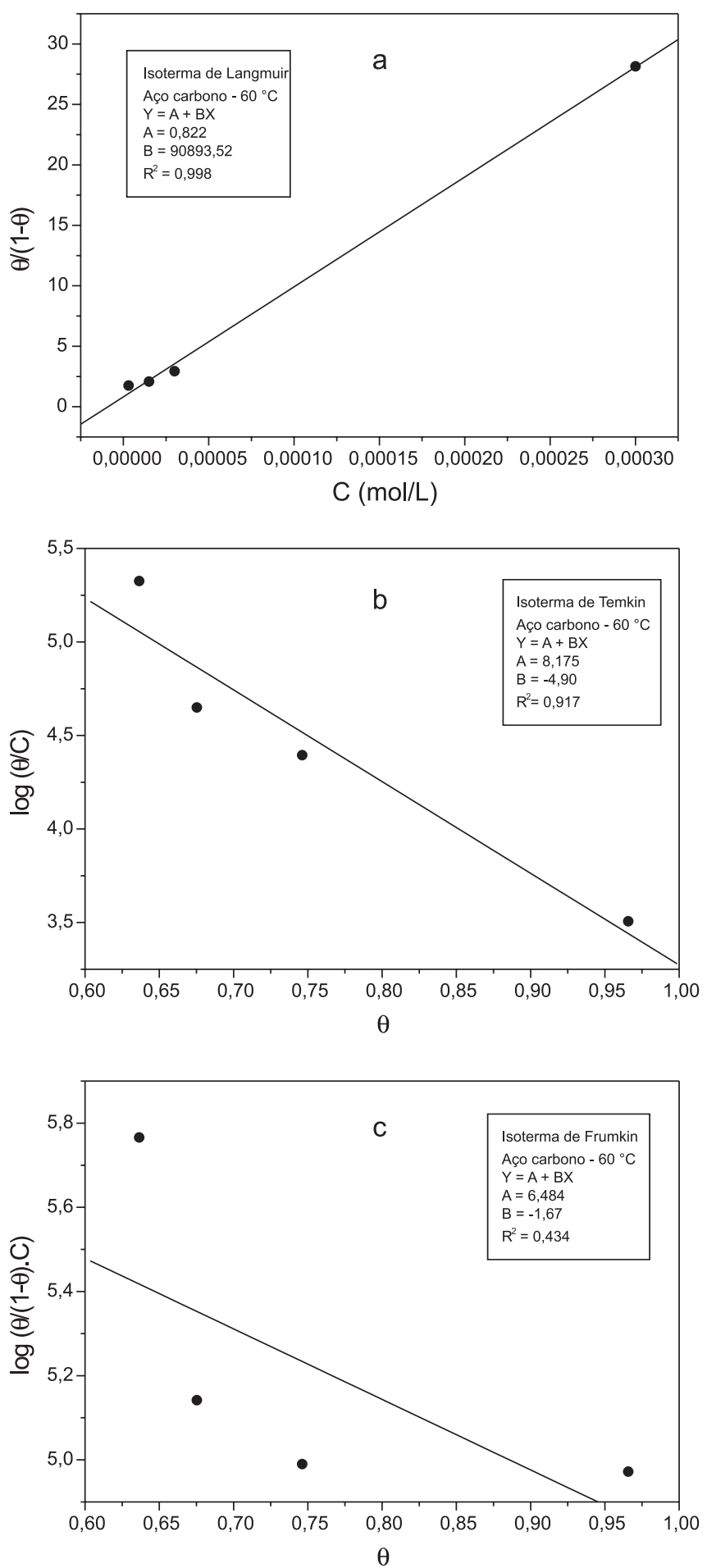

Figura 5. Isoterma de Langmuir (a), Temkin (b) e Frumkin (c) para o aço carbono a $60^{\circ} \mathrm{C}$ na presença de $\mathrm{HCl} 15 \% \mathrm{p} / \mathrm{v}+$ fluoresceína + formaldeído $0,6 \% \mathrm{p} / \mathrm{v}$

A $60{ }^{\circ} \mathrm{C}$, a fluoresceína e o alaranjado de metila proporcionaram taxa de corrosão acima de 200 mpy.

A adição de etanol e/ou formaldeído acarretou aumento na eficiência da fluoresceína, com a mistura fluoresceína $1 \% \mathrm{p} / \mathrm{v}+$ formaldeído $0,6 \%$ p/v gerando taxa de corrosão de 140,01 mpy. Este valor é comparável às taxas de corrosão encontradas para o aço carbono, quando do uso de inibidores comerciais.

Os resultados das curvas de polarização confirmaram o poder 
de inibição da mistura fluoresceína $1 \% \mathrm{p} / \mathrm{v}$ + formaldeído $0,6 \% \mathrm{p} /$ $\mathrm{v}$, verificado nos ensaios de perda de massa. $\mathrm{O}$ uso desta mistura proporciona a redução da corrente anódica frente ao branco.

Pelos diagramas de Nyquist observou-se que a adição da fluoresceína e aditivo acarretou um aumento no valor de $\mathrm{R}_{\mathrm{tc}}$, quando comparado ao ensaio em branco, indicando maior proteção do metal. No entanto, os valores de $\mathrm{R}_{\mathrm{tc}}$ tendem a diminuir com o aumento da temperatura, sugerindo menor proteção do aço.

Das isotermas de adsorção testadas, o melhor ajuste foi para a isoterma de Langmuir com $\mathrm{R}^{2}=0,998$, com uma variação de energia livre de $-42,72 \mathrm{KJ} / \mathrm{mol}$, caracterizando-se como adsorção química.

Mediante os ensaios realizados verificou-se que o uso da fluoresceíma e aditivo é viável na formulação de inibidores para o aço carbono em $\mathrm{HCl}$. A principal vantagem do uso da fluoresceína como matéria ativa em formulações de inibidores de corrosão em meio ácido, quando comparada a inibidores comerciais e compostos sugeridos na literatura, está em seu baixo custo e no fato de não ser uma substância tóxica. Deve-se destacar que parte significativa dos inibidores usualmente empregados para este fim possuem como matéria ativa substâncias tóxicas ou irritantes, o que confere à fluoresceína um diferencial interessante. É necessário ainda identificar a melhor concentração a ser usada levando-se em consideração custo/solubilidade/eficiência, e serem realizados testes contendo os aditivos comercialmente usados nas formulações de inibidores em meio ácido.

\section{REFERÊNCIAS}

1. Pereira, A. Z.; Motta, E. P. Da; Rio Oil \& Gas Expo and Conference, Rio de Janeiro, Brasil, 2000; http://www/dep.fem.unicamp.br/boletim/BE17/ artigo_Dore.htm, acessada em Novembro 2002.

2. Williams, B. B.; Gidley, J. L.; Schechter, R. S., eds.; Acidizing Fundamentals, Society of Petroleum Engineers of AIME: USA, 1979.

3. Schmitt G.; European Federation of Corrosion Publications, Published for The European of Corrosion by The Institute of Materials: London, 1994, $\mathrm{n}^{\circ} 11$, chapter 5 .

4. Jóia, C. J. B. M.; Brito, R. F.; Barbosa, B. C.; Moraes, F. D.; Pereira, A. Z. I.; Marques, L. C. C.; Corrosion 2001, 57, 1007.

5. Gentil, V.; Corrosão, $3^{a}$ ed., LTC-Livros Técnicos e Científicos S.A.: Rio de Janeiro, 1996; Silva, P. F. Da; Introdução à corrosão e proteção das superfícies metálica, Imprensa Universitária da UFMG: Belo Horizonte, 1981; West, J. M.; Electrodeposition and Corrosion Processes, The Camelot Press LTD: London, 1965.

6. NORMA ASTM G1-72: "Preparing, cleaning and evaluating corrosion test speciments".

7. Guedes, I. C.; Aoki, I. V.; Anais do $18^{\circ}$ Congresso Brasileiro de Corrosão, Rio de Janeiro, Brasil, 1995.

8. Oliveira, G. S. de; Dissertação de Mestrado, Universidade Federal do Rio de Janeiro, Brasil, 2002.

9. Bentis, F.; Traisnel, M.; Lagrenee, M.; Corros. Sci. 2000, 42, 127.

10. Atkins, P. W.; Físico-Química, $6^{\mathrm{a}}$ ed., LTC - Livros Técnicos e Científicos Ed. S.A.: Rio de Janeiro, 1999, vol. 3; http://www.aue.auc.dk/ stoltze/catal/ book, acessada em Março 2003. 